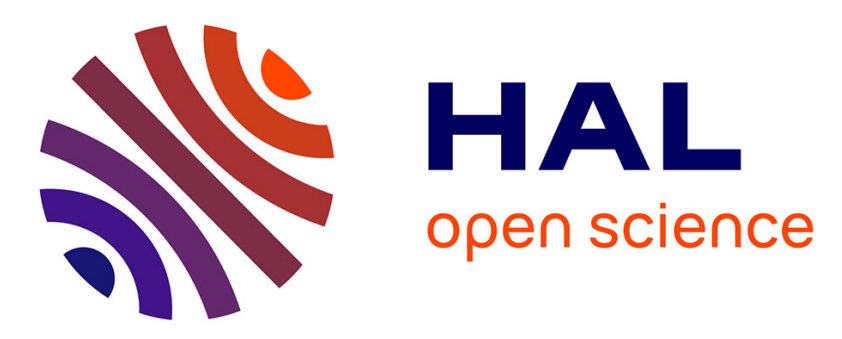

\title{
Influence of series resistance on the experimental extraction of FinFET noise parameters
} Angeliki Tataridou, Gérard Ghibaudo, Christoforos Theodorou

\section{To cite this version:}

Angeliki Tataridou, Gérard Ghibaudo, Christoforos Theodorou. Influence of series resistance on the experimental extraction of FinFET noise parameters. 2020 IEEE 33rd International Conference on Microelectronic Test Structures (ICMTS), May 2020, Edinburgh, United Kingdom. pp.1-4, 10.1109/ICMTS48187.2020.9107908 . hal-02969736

\section{HAL Id: hal-02969736 \\ https://hal.science/hal-02969736}

Submitted on 27 Dec 2020

HAL is a multi-disciplinary open access archive for the deposit and dissemination of scientific research documents, whether they are published or not. The documents may come from teaching and research institutions in France or abroad, or from public or private research centers.
L'archive ouverte pluridisciplinaire HAL, est destinée au dépôt et à la diffusion de documents scientifiques de niveau recherche, publiés ou non, émanant des établissements d'enseignement et de recherche français ou étrangers, des laboratoires publics ou privés. 


\title{
Influence of series resistance on the experimental extraction of FinFET noise parameters
}

\author{
Angeliki Tataridou, Gerard Ghibaudo and Christoforos Theodorou \\ IMEP-LAHC \\ Univ. Grenoble Alpes, Univ. Savoie Mont Blanc, CNRS, Grenoble INP* \\ Grenoble, 38000, France \\ *Institute of Engineering Univ. Grenoble Alpes \\ e-mail: angeliki.tataridou@grenoble-inp.fr
}

\begin{abstract}
In this paper we demonstrate for the first time how the series resistance of an advanced CMOS device, such as the FinFET, can lead to an incorrect extraction of low-frequency noise parameters. In particular, the use of the carrier number fluctuations with correlated mobility fluctuations model is shown to be very sensitive to the transistor series resistance. We demonstrate how the classic fitting methods can lead to an underestimated value in the extraction of the mobility fluctuations factor $\Omega$. Furthermore, we present an original method for suppressing this effect, by taking advantage of the series resistance immune $Y$-function.
\end{abstract}

\section{INTRODUCTION}

Low frequency noise (LFN) is attracting more and more interest in the last years, since it not only characterizes a device performance in terms of dynamic stability [1], but can also give significant information about the defects inside the oxide [2] or silicon [3] which is valuable especially in today's aggressively scaled devices like FinFETs [4], [5]. The utilization of LFN for the assessment of the oxide/silicon interface quality requires the reliable extraction of noise parameters such as the trap density, $\mathrm{N}_{\mathrm{t}}$, and the remote Coulomb scattering coefficient, $\alpha_{\text {sc }}$.

This extraction is achieved using the well-established [6], [7], [8] carrier number fluctuations with correlated mobility fluctuations (CNF/CMF) model (1), which considers both the change of the flat-band voltage $\left(\mathrm{V}_{\mathrm{FB}}\right)$ following the trapping/detrapping of free carriers and the mobility change due to the interface charge fluctuations [6].

$$
\frac{\mathrm{S}_{\mathrm{I}_{\mathrm{d}}}}{\mathrm{I}_{\mathrm{d}}{ }^{2}}=\left(1+\Omega \frac{\mathrm{I}_{\mathrm{d}}}{\mathrm{g}_{\mathrm{m}}}\right)^{2}\left(\frac{\mathrm{g}_{\mathrm{m}}}{\mathrm{I}_{\mathrm{d}}}\right)^{2} \mathrm{~S}_{\mathrm{V}_{\mathrm{FB}}}
$$

$\mathrm{S}_{\mathrm{Vfb}}$ is the flat-band voltage fluctuations power spectral density, and $\Omega$ is the CMF coefficient given by (2).

$$
\mathrm{S}_{\mathrm{V}_{\mathrm{FB}}}=\frac{\mathrm{q}^{2} \lambda \mathrm{kTN}_{\mathrm{t}}}{\mathrm{WLC}_{\mathrm{ox}}^{2} f^{\gamma}}, \Omega=\alpha_{\mathrm{sc}} \mu_{\mathrm{eff}} \mathrm{C}_{\mathrm{ox}}
$$

where, $\mu_{e f f}$ is the effective mobility and $C_{o x}$ the oxide capacitance per unit area, $\lambda$ is the tunneling constant in the dielectric $(\approx 0.1 \mathrm{~nm}), \mathrm{kT}$ is the thermal voltage, $\mathrm{q}$ is the elementary charge of electrons, $f$ the frequency, $\gamma$ the characteristic exponent close to $1, \mathrm{~N}_{\mathrm{t}}$ the volumetric trap density and W, L the channel width and length respectively.
This extraction is generally reliable in the case of long channel devices. However in short channel devices, the series resistance $\left(\mathrm{R}_{\mathrm{SD}}\right)$ can degrade a FinFET's performance because it becomes important with respect to the reduced channel resistance. Therefore, the use of experimentally measured quantities such as the device extrinsic transconductance, $g_{m}$, for the noise parameter extraction through (1) may jeopardize the precision of the extraction procedure. In this work we study, for the first time, the impact of $\mathrm{R}_{\mathrm{SD}}$ on the low-frequency noise (LFN) parameter extraction.

\section{EXPERIMENTAL APPROACH AND DEVICE UNDER TEST}

A very useful quantity in the LFN characterization and modeling is the input-referred gate voltage noise $\mathrm{S}_{\mathrm{Vg}}=\mathrm{S}_{\mathrm{Id}} /$ $\mathrm{g}_{\mathrm{m}}{ }^{2}$. It suppresses the impact of $\mathrm{g}_{\mathrm{m}}$ on the measured noise and expresses every fluctuation as a gate voltage variation, which allows for easier model implementations in circuit simulations. Concerning its application in the extraction of LFN parameters, a method very often used by our team in recent works [7], [8] is to extract $\Omega$ from the slope of $\sqrt{S_{V g}}$ vs $\mathrm{I}_{\mathrm{d}} / \mathrm{g}_{\mathrm{m}}$, thanks to the expression of (3):

$$
\sqrt{S_{V_{g}}}=\sqrt{S_{V_{F B}}}\left(1+\Omega \frac{I_{d}}{g_{m}}\right)
$$

which is derived from (1) after normalizing with $\left(\mathrm{g}_{\mathrm{m}} / \mathrm{I}_{\mathrm{d}}\right)^{2}$.

Nevertheless, this method is obviously sensitive to the $I_{d} / g_{m}$ factor, which in turn is influenced by the presence of

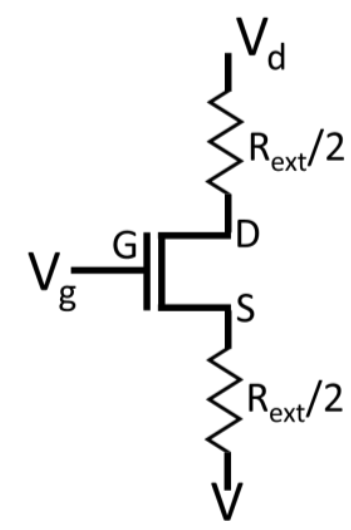

Fig. 1. Experimental set-up for monitoring the $\mathrm{R}_{\mathrm{SD}}$ influence. 
$\mathrm{R}_{\mathrm{SD}}$. For this reason, it is rather questionable whether the extraction of $\Omega$ by this established method is reliable. In order to monitor how the increase of $\mathrm{R}_{\mathrm{SD}}$ can impact the extraction of $\Omega$, we repeated the same LFN measurements on the same FinFET device for various combinations of externally connected resistors, $\mathrm{R}_{\mathrm{ext}}$, at both the drain $\left(\mathrm{R}_{\mathrm{ext}} / 2\right)$ and source $\left(\mathrm{R}_{\mathrm{ext}} / 2\right)$ terminals. The setup schematic is shown in Fig. 1.

The device under study is a n-channel FinFET fabricated at IMEC-Leuven, with number of fins $\mathrm{N}_{\text {fin }}=22 \mathrm{~nm}$, fin height $\mathrm{H}_{\text {fin }}=26 \mathrm{~nm}$, channel length $\mathrm{L}=28 \mathrm{~nm}$ and fin width $\mathrm{W}_{\text {fin }}=$ $4.5 \mathrm{~nm}$. The LFN measurements were performed using the programmable bias point probe system NOISYS7 [9], combined with a semi-auto $300 \mathrm{~mm}$ Cascade Micro Tech probe station. The simulations were performed using the FlexPDE [10] solver and the Python Spyder [11] platform.

\section{RESUlTS AND DISCUSSION}

Measurements of static $\mathrm{I}_{\mathrm{d}}\left(\mathrm{V}_{\mathrm{g}}\right)$ transfer characteristics were performed in linear region $\left(V_{d}=30 \mathrm{mV}\right)$ for different $R_{\text {ext }}$ values. As shown in Fig. 2, there is a significant drain current degradation with $\mathrm{R}_{\mathrm{ext}}$ in strong inversion.

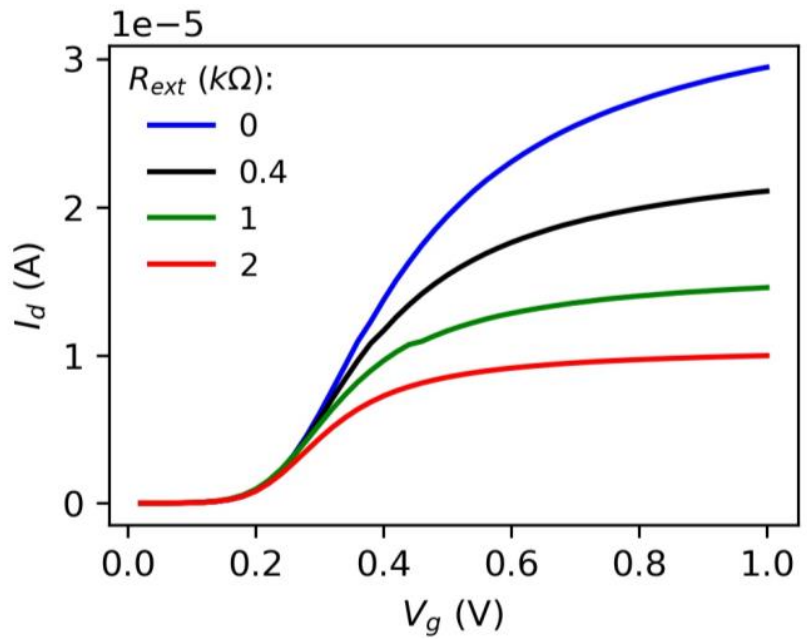

Fig. 2. Drain current versus gate voltage characteristics for various values of external resistance, $R_{\text {ext }}$.

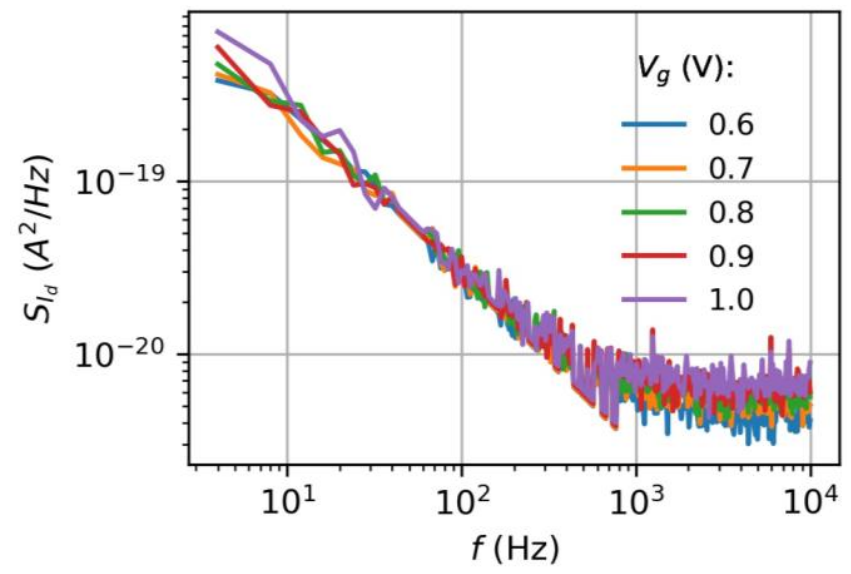

Fig. 3. Drain current noise power spectral density versus frequency for zero external resistance, $\mathrm{R}_{\mathrm{ext}}=0 \Omega$ at various gate bias values in strong inversion.

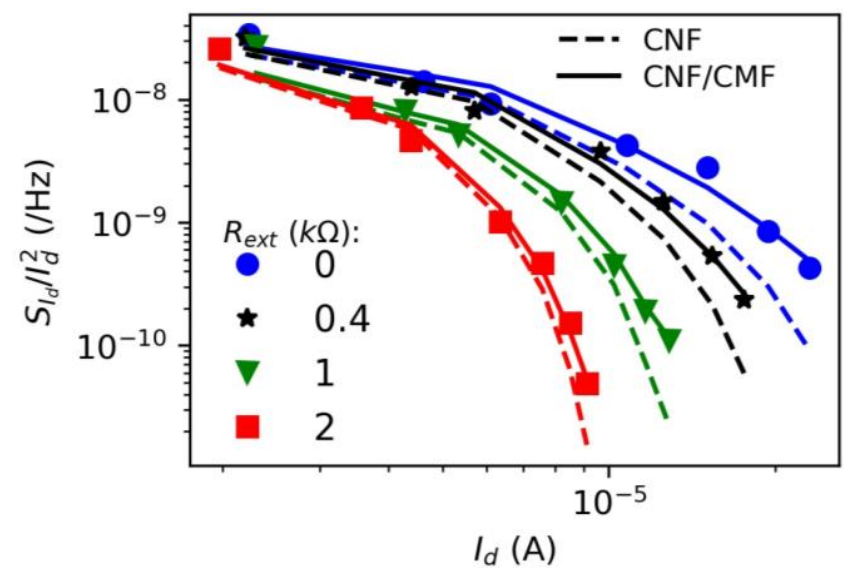

Fig. 4. Normalized drain current noise vs drain current along with the $\mathrm{CNF}$ and CNF/CMF fitting models for the different external resistance values, $R_{\text {ext }}$.

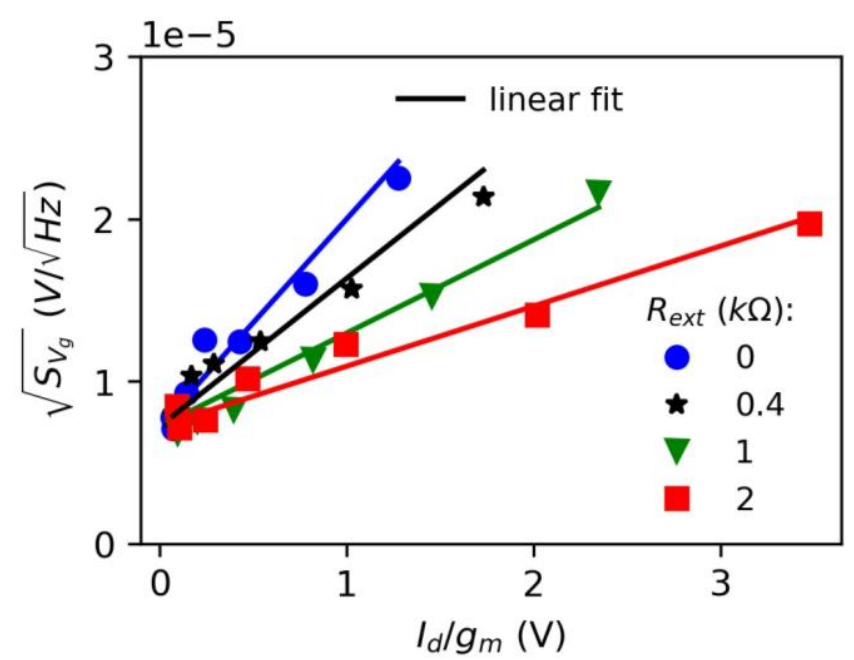

Fig. 5. Square root of input-referred noise, $\sqrt{S_{\mathrm{Vg}}}$, versus the ratio of drain current and transconductance, $\mathrm{I}_{\mathrm{d}} / \mathrm{g}_{\mathrm{m}}$, for various external resistance values.

The next step is to study what is the impact of this phenomenon on the noise characterization. In Fig. 3, where the measured drain current noise spectral density is plotted versus frequency, one can observe a pure 1/f-like behavior, allowing us to apply the CNF/CMF model for the mean PSD value around $10 \mathrm{~Hz}$.

Fig. 4 shows the plots of $S_{I d} / I_{d}{ }^{2}$ around $10 \mathrm{~Hz}$ versus $I_{d}$ for four different $R_{\text {ext }}$ values along with the corresponding $\mathrm{CNF} / \mathrm{CMF}$ model fit in the strong inversion region where the influence of $\mathrm{R}_{\mathrm{SD}}$ takes place. The dotted lines represent the $\mathrm{CNF} / \mathrm{CMF}$ model with $\Omega=0$, to visualize how a high value of series resistance can make one think that there is no mobility fluctuations (CMF) contribution. Indeed, one can observe that as the series resistance increases, the experimental data approach the CNF model, eliminating almost completely the influence of CMF coefficient $\Omega$ in the maximum $R_{\text {ext }}$ case (2 $\mathrm{k} \Omega$ ).

The same behavior can also be observed from the $\sqrt{ } S_{V g}$ vs $\mathrm{I}_{\mathrm{d}} / \mathrm{g}_{\mathrm{m}}$ plot shown in Fig. 5, where we note that the slope of the characteristics changes with $\mathrm{R}_{\mathrm{ext}}$. This behavior with the series 


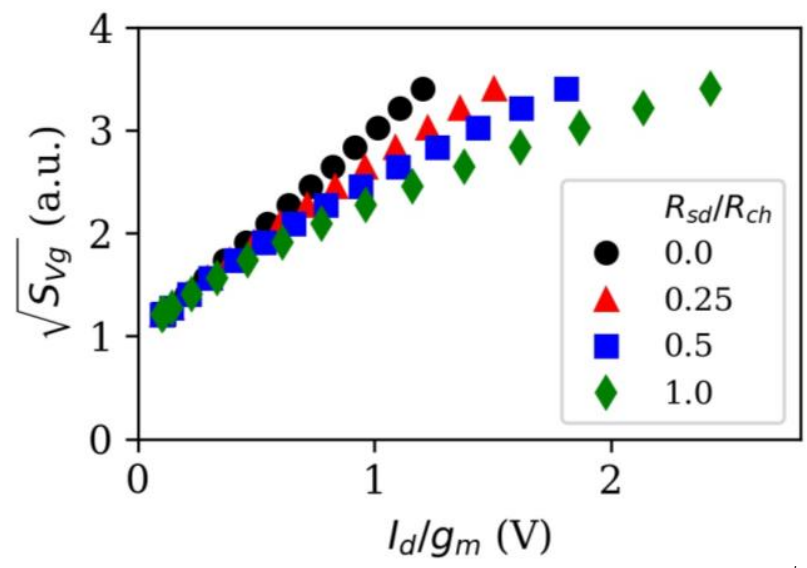

Fig. 6. Simulation results of square root of input-referred noise, $\sqrt{ } \mathrm{S}_{\mathrm{Vg}}$, versus the ratio of drain current and transconductance, $I_{d} / g_{m}$ for various $\mathrm{R}_{\mathrm{SD}} / \mathrm{R}_{\mathrm{CH}}$ ratios.

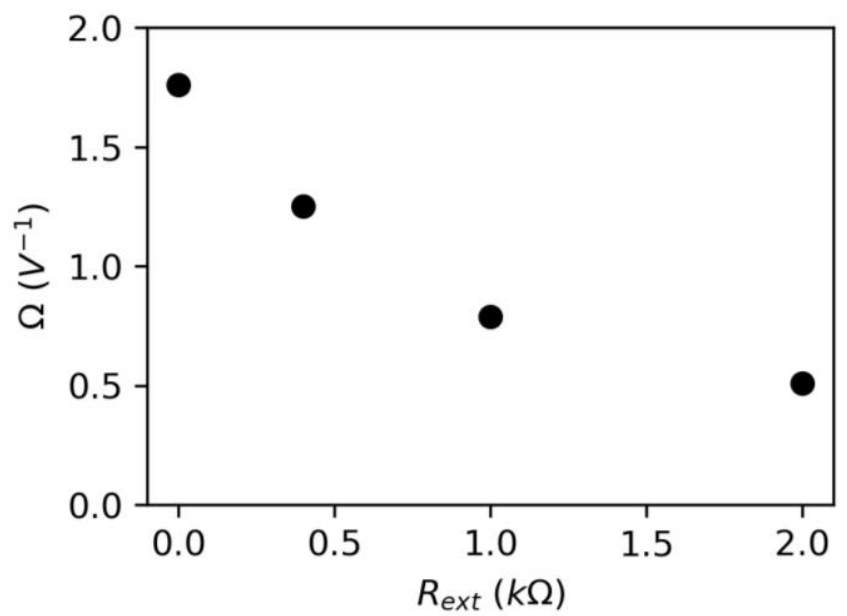

Fig. 7. Extracted CMF factor $\Omega$ versus the different $R_{\text {ext }}$ values.

resistance was also confirmed by simulations, as shown in Fig. 6 , where $R_{c h}=V_{d} / I_{d}$ is the channel resistance in ohmic region. This effect takes place because the presence of $R_{\text {ext }}$ degrades $\mathrm{g}_{\mathrm{m}} / \mathrm{I}_{\mathrm{d}}$, thus leading to an increase of the $\mathrm{I}_{\mathrm{d}} / \mathrm{g}_{\mathrm{m}}$ ratio, and shifts the experimental data points to the right, resulting to the unreliable extraction of the CMF factor $\Omega$. Combining this finding with the fact that the intercept remains the same for all $R_{\text {ext }}$ values and thus a constant value of $S_{V f b}$ can be extracted, we conclude that the diverging characteristics will lead in an underestimation of the $\Omega$ factor. By extracting $S_{\mathrm{Vfb}}$ from Fig. 4 and by taking a mean value of $5.24 \times 10^{-11} \mathrm{~V}^{2} / \mathrm{Hz}$ for $S_{\mathrm{Vfb}}$, we pursued to the linear fit of (3) in Fig. 5 in order to calculate the $\Omega$ coefficient for the different $\mathrm{R}_{\mathrm{ext}}$. The dependence of this 'apparent' $\Omega$ on the presence of $\mathrm{R}_{\text {ext }}$ can be seen in Fig. 7. As expected, the extracted $\Omega$ factor is reduced with $R_{\text {ext }}$, revealing an underestimation due to the specific extraction process.

\section{NEW EXTRACTION METHODOLOGY}

To eliminate the impact of $\mathrm{R}_{\mathrm{SD}}$ on the $\Omega$ extraction we can take advantage of the $\mathrm{Y}$ function, which is immune to the influence of series resistance [12] and is given by (4):

$$
\mathrm{Y}=\mathrm{I}_{\mathrm{d}} / \sqrt{\mathrm{g}_{\mathrm{m}}}
$$

Fig. 8 depicts the Y-function plot for all the cases implying that the $\mathrm{R}_{\mathrm{ext}}$ has been successfully compassed from the drain current. Henry et al. [13] published a new Y-function extraction method where $\mathrm{I}_{d} / \mathrm{g}_{\mathrm{m}}$ can be replaced as in (5):

$$
\frac{\mathrm{I}_{\mathrm{d}}}{\mathrm{g}_{\mathrm{m}}}=\mathrm{n} \frac{\mathrm{kT}}{\mathrm{q}}+\frac{\mathrm{Y}}{\sqrt{\beta}}
$$

where $\mathrm{n}$ is the transistor ideality factor and $\beta=\mathrm{V}_{\mathrm{d}} \mu_{0} \mathrm{C}_{\mathrm{ox}} \mathrm{W} / \mathrm{L}$ its gain factor.

The combination of (4) and (5) considering that nkT/q is negligible in the strong inversion region results to (6):

$$
\sqrt{S_{\mathrm{V}_{\mathrm{g}}}}=\sqrt{\mathrm{S}_{\mathrm{V}_{\mathrm{FB}}}}\left[1+\Omega\left(\frac{\mathrm{Y}}{\sqrt{\beta}}\right)\right]
$$

Therefore, if we plot $\sqrt{ } S_{V g}$ vs $\mathrm{Y}$ instead of $\mathrm{I}_{\mathrm{d}} / \mathrm{g}_{\mathrm{m}}$, as shown in Fig. 9, we can obtain a linear dependence which is not affected by the change in $R_{\text {ext }}$. This way a new, $R_{\mathrm{SD}^{-}}$ independent value of $\Omega$ can be extracted, combining all groups of points. We extracted a value of $\Omega=6.5 \mathrm{~V}^{-1}$, much higher than the one extracted when $R_{\text {ext }}=0 \Omega\left(1.75 \mathrm{~V}^{-1}\right)$, revealing that the CMF contribution can indeed be completely overshadowed by the presence of a high series resistance value.

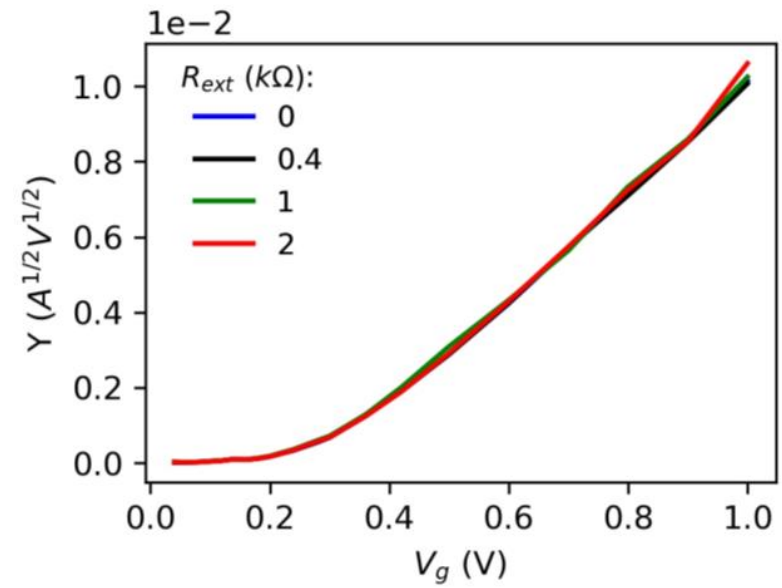

Fig. 8. Y-function versus gate voltage for the different external resistance values.

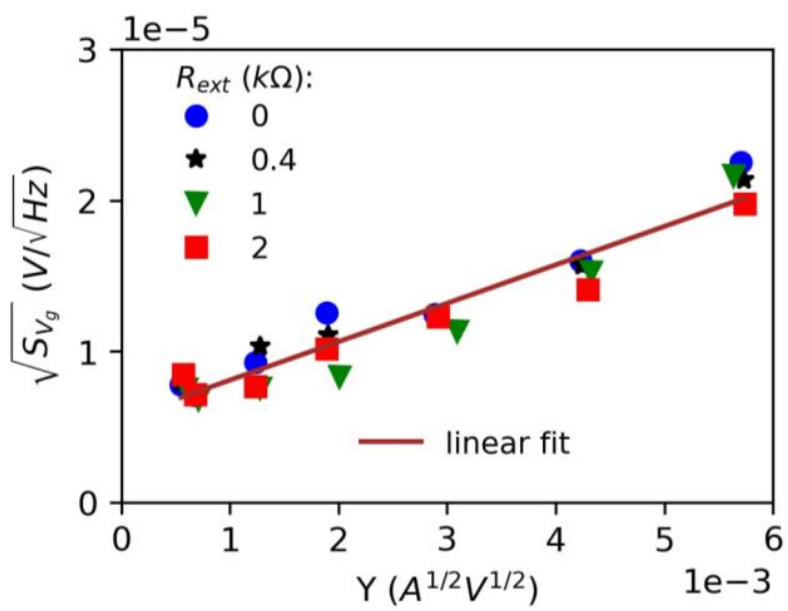

Fig. 9. Square root of input-referred noise versus $Y$-function for the different external resistance values, $\mathrm{R}_{\mathrm{ext}}$. 


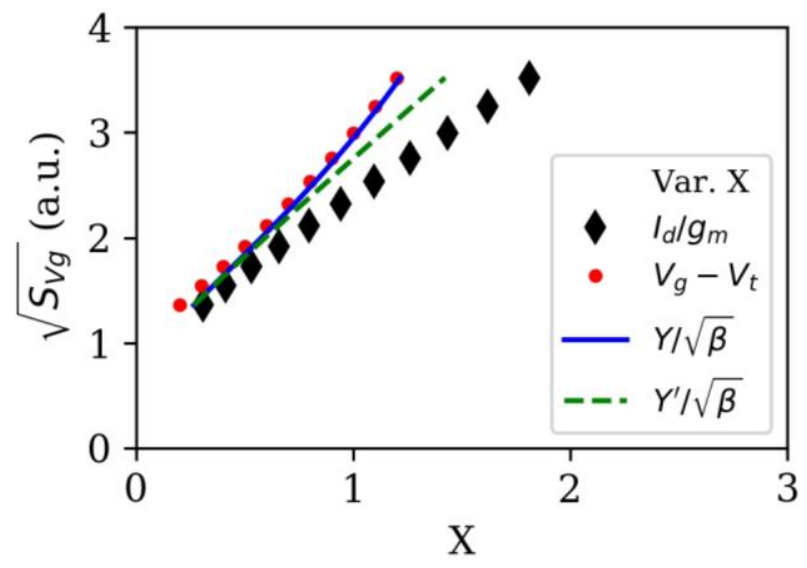

Fig. 10. Simulation results of square root of input-referred noise, $\sqrt{S_{\mathrm{Vg}}}$, versus different $X$ variables.

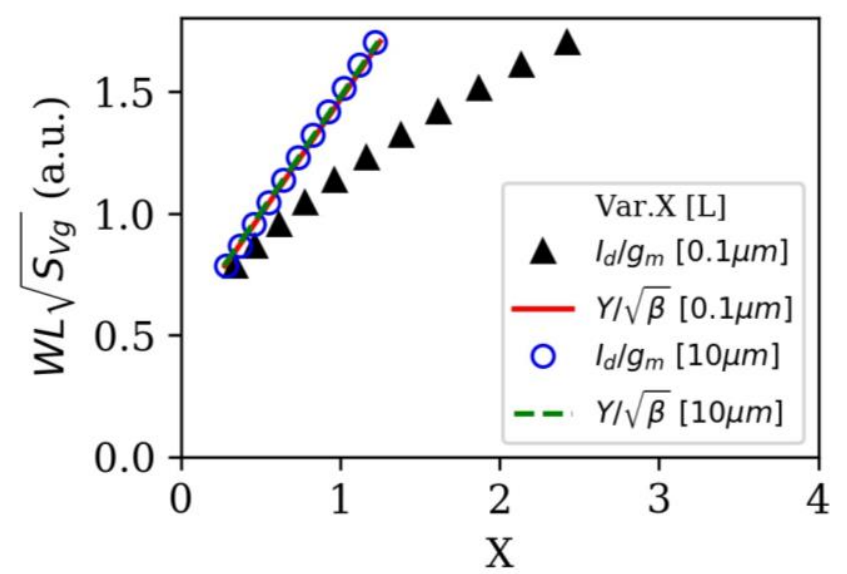

Fig. 11. Simulation results of normalized with area square root of input-referred noise, $\mathrm{WL} \sqrt{ } \mathrm{S}_{\mathrm{Vg}}$, versus different $\mathrm{X}$ variables.

It might be argued that by plotting $\sqrt{ } S_{V g}$ versus $\left(\mathrm{V}_{\mathrm{g}}-\mathrm{V}_{\mathrm{t}}\right)$ would also give a straight line, but this is true when the mobility is degraded only due to the series resistance through the first order attenuation factor $\theta_{1} \approx \beta * \mathrm{R}_{\mathrm{SD}} / \mathrm{V}_{\mathrm{d}}$. However, in the possible presence of the second order mobility attenuation factor $\theta_{2}$, the linearity with $\mathrm{V}_{\mathrm{g}}-\mathrm{V}_{\mathrm{t}}$ is lost [14]. But if we use the Y-function expression (7) [12] that accounts for the influence of $\theta_{2}$, a great linearity is achieved, as illustrated in Fig. 10, allowing for the proper extraction of $\Omega$.

$$
\mathrm{Y}^{\prime}=\sqrt{\frac{\beta}{1-\theta_{2}\left(V_{g}-V_{t}\right)^{2}}}\left(V_{g}-V_{t}\right)
$$

Moreover, concerning the channel length influence on this effect, since the impact of series resistance becomes negligible in long channel devices, we expect that both $\mathrm{I}_{d} / \mathrm{g}_{\mathrm{m}}$ and $\mathrm{Y}$ function methods will give the same results. This was confirmed by simulations, where a 100 times longer channel was tested, for the same value of $R_{S D}=1 \mathrm{k} \Omega$. As can be seen in Fig. 11, the series resistance affects significantly the $\mathrm{L}=$ $0.1 \mu \mathrm{m}$ parameter extraction, whereas for $\mathrm{L}=10 \mu \mathrm{m}$ there is no $\mathrm{R}_{\mathrm{SD}}$ influence on the extraction precision. Therefore, the Y- function method we propose is valid regardless the channel length.

\section{CONCLUSION}

The impact of $R_{S D}$ on the extraction of noise parameters and especially on the $\Omega$ coefficient has been studied for FinFETs of $4.5 \mathrm{~nm}$ wide channel. It was found that the degradation of $g_{m} / I_{d}$ due to the presence of $R_{S D}$ results to the unreliable extraction of $\Omega$ and in high values of $R_{\mathrm{SD}}$ the mobility fluctuation due to charged traps can be heavily underestimated. To respond to this challenge, a new extraction methodology is proposed which utilizes the Y-function to successfully eliminate the $\mathrm{R}_{\mathrm{SD}}$ influence.

\section{ACKNOWLEDGMENT}

The authors would like to acknowledge the Horizon 2020 ASCENT EU project (Access to European Nanoelectronics Network -Project no. 654384). They would also like to thank Thomas Chiarella and Jerome Mitard from IMEC-Leuven for their technical help and general support.

\section{REFERENCES}

[1] G. Ghibaudo, O. Roux-dit-Buisson, and J. Brini, "Impact of Scaling Down on Low Frequency Noise in Silicon MOS Transistors," Phys. Status Solidi, vol. 132, no. 2, pp. 501-507, Aug. 1992.

[2] D. M. Fleetwood, "1/f Noise and Defects in Microelectronic Materials and Devices," IEEE Trans. Nucl. Sci., vol. 62, no. 4, pp. 1462-1486, 2015.

[3] N. B. Lukyanchikova, M. V Petrichuk, N. P. Garbar, E. Simoen, and C. Claeys, "Non-trivial GR and 1/f noise generated in the p-Si layer of SOI and SOS MOSFETs near the inverted front or buried $\mathrm{p}-\mathrm{Si} / \mathrm{SiO} 2$ interface," Semicond. Sci. Technol., vol. 14, no. 9, pp. 775-783, 1999.

[4] C. G. Theodorou, N. Fasarakis, T. Hoffman, T. Chiarella, G. Ghibaudo, and C. A. A. Dimitriadis, "Flicker noise in n-channel nanoscale tri-gate fin-shaped field-effect transistors," Appl. Phys. Lett., vol. 101, no. 24, p. 243512, 2012

[5] H. Achour et al., "In depth static and low-frequency noise characterization of n-channel FinFETs on SOI substrates at cryogenic temperature," Solid. State. Electron., vol. 98, pp. 12-19, 2014.

[6] G. Ghibaudo, O. Roux, C. Nguyen-Duc, F. Balestra, and J. Brini, "Improved Analysis of Low Frequency Noise in Field-Effect MOS Transistors," Phys. Status Solidi, vol. 124, no. 2, pp. 571-581, 1991.

[7] E. G. Ioannidis, C. A. Dimitriadis, S. Haendler, R. A. Bianchi, J. Jomaah, and G. Ghibaudo, "Improved analysis and modeling of lowfrequency noise in nanoscale MOSFETs," Solid. State. Electron., vol. 76, pp. 54-59, 2012.

[8] E. G. Ioannidis, C. G. Theodorou, T. A. Karatsori, S. Haendler, C. A. Dimitriadis, and G. Ghibaudo, "Drain-Current Flicker Noise Modeling in nMOSFETs From a 14-nm FDSOI Technology," IEEE Trans. Electron Devices, vol. 62, no. 5, pp. 1574-1579, 2015.

[9] J. A. Chroboczek, A. Szewczyk, and G. Piantino, "Low frequency noise point probe measurements on a wafer level using a novel programmable current amplifier," in Noise in Physical Systems and $1 / F$ Fluctuations, 2001, pp. 701-704.

[10] "Flex PDE." [Online]. Available: https://www.pdesolutions.com/.

[11] “Spyder IDE." [Online]. Available: https://www.spyder-ide.org/.

[12] D. Fleury, A. Cros, H. Brut, and G. Ghibaudo, "New Y-function-based methodology for accurate extraction of electrical parameters on nanoscaled MOSFETs," IEEE Int. Conf. Microelectron. Test Struct., pp. 160-165, 2008.

[13] J. B. Henry, Q. Rafhay, A. Cros, and G. Ghibaudo, "New Y-function based MOSFET parameter extraction method from weak to strong inversion range," Solid-State Electronics. 2016.

[14] T. Boutchacha and G. Ghibaudo, "Improved modeling of lowfrequency noise in MOSFETs - Focus on surface roughness effect and saturation region," IEEE Trans. Electron Devices, vol. 58, no. 9, pp. 3156-3161, 2011. 
